\title{
Os 60 Anos d'O Problema do Café no Brasil, de Delfim Netto
}

\section{Pedro Garcia Duarte ${ }^{1}$}

O ano de 2019 marca uma dupla importante efeméride do pensamento econômico brasileiro. Trata-se dos 60 anos da tese de livre-docência do Professor Antonio Delfim Netto, posteriormente publicada em livro de grande impacto, intitulada "O Problema do Café no Brasil." No mesmo ano de 1959, outra importante obra da historiografia econômica brasileira era publicada, Formação Econômica do Brasil, de Celso Furtado.

O Professor Delfim dispensa apresentações, mas acho importante ressaltar alguns aspectos da sua carreira para que tenhamos uma perspectiva adequada para entender seu trabalho celebrado na sessão especial da ANPEC 2019 por mim presidida, ocorrida na Fundação Getúlio Vargas, em São Paulo, no dia 13 de dezembro, com as participações de Flávio Versiani (UnB) e Marcos Lisboa (INSPER), além do próprio Delfim. Nascido em São Paulo em 1928, iniciou em 1944, aos 16 anos, a escola técnica de contabilidade, formando-se em 1947. Como ele disse em entrevista de 1995, sempre quis ser engenheiro, mas por ser de família modesta tinha que trabalhar, o que era impossível de ser feito conjuntamente ao curso de engenharia. Em setembro de 1945, o decreto-lei no. 7.988 normatizou o ensino superior de ciências econômicas e de ciências contábeis e atuariais no Brasil, permitindo que diplomados em cursos comerciais técnicos prestassem vestibular para ingresso nas universidades. Assim, aos 19 anos de idade, inicia em 1948 o recém-criado curso de economia da FEA-USP (criado em 1946), concluindo-o em 1951.

No ano seguinte, em 1952, é nomeado assistente do Professor Luiz de Freitas Bueno, que era catedrático da cadeira de Estatística I da FEA-USP.

1 Sênior Research Fellow - Insper Instituto de Ensino e Pesquisa - Endereço: Rua Quatá, 300 - Vila Olímpia - São Paulo/SP - Brasil - CEP: 04546-042 - E-mail: pedro.duarte@insper.edu.br.

ORCiD: https://orcid.org/0000-0003-3525-7036.

Editor Responsável: Dante Mendes Aldrighi

(c) (i) (\$) Esta obra está licenciada com uma Licença Creative Commons Atribuição-Não Comercial 4.0 Internacional. 
Em 1953, ministra um curso de análise matemática para economistas da Bolsa de Mercadorias de São Paulo (Hespanhol 2017, p. 9). Sete anos depois de se tornar assistente, defende sua tese de livre-docência, fazendo uma abordagem que combinava história com métodos quantitativos para estudar a economia brasileira. Ele assim anuncia no parágrafo inicial de sua tese:

"É muito difícil penetrar-se no âmago do problema cafeeiro e em todas as suas variadas implicações sobre a economia nacional sem o estudo minucioso da sua história. Aqui, como em todo problema da vida real, a aproximação metodológica que nos parece mais fecunda é através da história. É dessa observação que eventualmente nascerá um modelo abrangendo as variáveis mais importantes do fenômeno e que nos permitirá compreende-lo mais profundamente." (Delfim Netto 1959, p. 1)

Mais de trinta e cinco anos depois, naquela mesma entrevista de 1995, Delfim reafirma sua convicção da importância desta opção metodológica:

"Continuo achando que essa [combinação de história com método quantitativo] é a única forma de tentar entender a realidade. Primeiro porque um fato objetivo é extremamente duvidoso, a realidade é a que eu vejo, que tem explicações que são históricas na sua origem. Para entende-la, provavelmente, é preciso alguma forma de discriminar os fatos, que é quantitativa." (Delfim Netto 1996, p. 101)

Nove anos após a tese de Delfim, em 1968, Edmar Bacha defenderia sua tese de doutorado em Yale, orientada por Marc Nerlove e Albert Berry, também com uma análise econométrica do mercado de café e da política de preço brasileira (tese intitulada An Econometric Model for the World Coffee Market: the impact of Brazilian price policy). ${ }^{2}$ Bacha analisa o período de 1952 a 1967, com pouca sobreposição ao período analisado por Delfim, 1851-1956.

2 Um pequeno trecho inicial da tese de Bacha está disponível online em Yale (https://search.proquest. com/docview/302359042; acessado em 12/12/2019) 
É importante destacar, entretanto, o contexto em que a análise de Delfim foi feita, completamente distinto do de Bacha: com calculadoras de mesa, como relata seu orientando, Affonso Celso Pastore, também numa entrevista de 1995:

\begin{abstract}
"A tese sobre o café do Delfim feita em 1959, quando eu estava no segundo ano de faculdade, é uma tese de história, com econometria e com teoria econômica. Ele pegou um período histórico, e analisou as intervenções do café. Estou falando de 1959, prestem atenção, as calculadoras eram de mesa e calculavam-se logaritmos. Apesar daquilo, ele foi buscar os métodos mais modernos que poderia encontrar, fez o melhor que pode do ponto de vista de análise quantitativa, num tipo de orientação que é desse pessoal que andou tirando o Nobel de economia há uns dois anos, Fogel e o outro historiador da Califórnia, Douglas North. Delfim fez uma tentativa de aplicação do método de análise econômica, métodos quantitativos, a um evento histórico. Acho que é o ponto alto de toda a sua produção, dali pra frente reduziu a produção, direcionando-se para a política." (Pastore 1996, pp. 220-221)
\end{abstract}

Independentemente da informalidade típica das entrevistas, e das opiniões de Pastore, Delfim continuou ativo academicamente após sua livre-docência. ${ }^{3}$ Desde a conclusão de sua graduação até sua livre-docência, em 1959, Delfim publicou cerca de trinta artigos ou pequenas notas, majoritariamente na chamada Revista dos Mercados, publicada bimestralmente pela Bolsa de Mercadorias de São Paulo, mas também alguns em duas outras revistas, a Revista de Ciências Econômicas (editada pelo Ordem dos Economistas de São Paulo) e a Digesto Econômico (editada pela Associação Comercial de São Paulo). ${ }^{4}$ Em 1961, assume interinamente o cargo de professor catedrático da Cadeira XXV - Contabilidade Nacional; Economia Brasileira; Planejamento Governamental; Teoria do Desenvolvimento Econômico. Em 1962, publica um boletim desta cadeira intitulado "Alguns problemas do planejamento para o desenvolvimento”. Mas é em 1963 que defende sua

3 Veja também as lembranças de um dos alunos de Delfim, Roberto Macedo (2001).

4 Neste período, Delfim foi assessor do Departamento de Estatística e Estudos Econômicos da Bolsa de Mercadorias de São Paulo (1952-1954), e assessor da Diretoria da Associação Comercial de São Paulo (1954-1966). 
tese de cátedra, "Planejamento para o Desenvolvimento Econômico", e se torna professor catedrático efetivo da Cadeira XXV, aposentando-se em 1981. Esta tese foi publicada em livro pela Pioneira Editora em 1966.

Assim como em seu trabalho de 1962 mencionado, em que Delfim analisa um modelo de desenvolvimento, partindo do caso simples de coeficientes fixos para uma função de produção neoclássica à la Solow (1956), dois outros artigos ilustram muito bem as preocupações de Delfim Netto com desenvolvimento econômico, tema de sua cátedra na FEA, e sua abordagem metodológica. O primeiro foi publicado em 1958 na Revista dos Mercados, e republicado em 1959 na Econômica Brasileira, uma revista editada pelo Clube de Economistas, fundado por Celso Furtado. ${ }^{5}$ Trata-se da análise de um artigo de 1952 de Furtado, que se tornou um capítulo de seu livro de 1954, A Economia Brasileira, com uma "Formulação Teórica do Problema do Crescimento Econômico". Neste artigo, Furtado usa a ideia keynesiana da distinção das "motivações psicológicas do agente que poupa" e do "agente que inverte" para discutir crescimento econômico. Delfim constrói um modelo matemático, sem qualquer recurso à história, de equações a diferenças lineares de primeira ordem para poder comparar Furtado com os modelos de "Domar, Harrod, Lundberg e outros" (Delfim Netto 1959, p. 58). No mesmo número da revista, há também uma versão estocástica deste modelo de Furtado feita por Raimundo Paes Barreto, professor da então Universidade do Brasil.

O segundo artigo que gostaria de destacar é publicado em 1966 em coautoria com o historiador econômico de Harvard, Nathaniel Leff, no Journal of Development Studies. Leff, após concluir seu mestrado em Columbia em 1962 (Seyler 1966, p. 799), mudou-se para o Brasil no final de 1963, morando em São Paulo por pouco mais de um ano. Neste período, encontrou-se com Delfim e visitou os seminários da FEA-USP. ${ }^{6}$ Leff fez sua tese de doutorado no departamento de ciência política do MIT (intitulada The Brazilian capital goods industry: economic policy and economic development), que concluiu em $1966 .^{7}$ Neste artigo coautorado, um modelo mate-

5 Veja a história desse clube e sua revista em Andrada, Boianovsky e Cabello (2018).

6 Pastore relembra este episódio em entrevista a Rafael Cariello (2016, p. 24): “'Um dia apareceu lá, num dos nossos seminários da USP, um sujeito meio careca, que falava depressa", contou Pastore. "Era o Nat Leff. Ele arranhava o português. Nós arranhávamos o inglês. Dava a impressão de ser um pesquisador extremamente curioso, que estava tentando entender quais eram as forças que haviam levado o Brasil a um processo de industrialização."”

7 É incorreta, portanto, a lembrança da esposa de Leff de que ele teria feito o doutorado em Columbia sob a orientação de Albert Hirschman (Cariello 2016, p. 24) (Seyler 1966). O registro da biblioteca do MIT aponta que seu orientador foi Frank Bonilla (http://library.mit.edu/item/000616091; 
mático de equações a diferenças é utilizado para analisar o crescimento da renda nacional e os impactos de longo prazo sobre o balanço de pagamentos. Há a utilização de dados da economia brasileira após a segunda guerra, comparando alguns de seus indicadores com os de outras economias.

O uso criativo de modelos para entender a economia brasileira e sua história foi uma marca da carreira de Delfim, que na segunda metade da década de 1960 cultivou mais sua carreira política e de formulador de política econômica. ${ }^{8}$ Mas aquele traço foi o que Maria da Conceição Tavares destacou em entrevista de 1995, ao ser perguntada se somos colonizados academicamente:

"Eu não posso chamar o Delfim [Netto] de colonizado academicamente, posso? Os mais velhos não são colonizados academicamente, usavam os "modelos" à disposição com a maior tranquilidade. O pensamento era eclético." (Tavares 1996, p. 140)

Sessenta anos depois, sua tese de livre-docência continua sendo amplamente utilizada para entender a economia cafeeira do final do século XIX e primeira metade do século XX. É por isto que foi muito mais que merecida a homenagem a esta obra e seu autor na sessão especial da ANPEC de 2019. Após a sessão, Versiani, Lisboa e Delfim prepararam os textos que acompanham esta introdução.

acessado em 12/12/2019). Sua tese foi publicada em 1968 como o livro The Brazilian capital goods industry, 1929-1964.

8 Delfim foi Secretário da Fazenda do Estado de São Paulo (1966-67), Ministro da Fazenda de 1967 a 1974, Embaixador do Brasil na França (1975-77), Ministro da Agricultura (de março a agosto de 1979), Ministro Chefe da Secretaria de Planejamento da Presidência da República (1979-85), e Deputado Federal por São Paulo por cinco legislaturas (1986, 1990, 1994, 1998 e 2002). 


\section{Referências}

Andrada, Alexandre F. S.; Boianovsky, Mauro; Cabello, Andrea F. "O Clube de Economistas e a Revista Econômica Brasileira (1955-1964): Um Episódio na História do Desenvolvimentismo Nacionalista no Brasil”. Estudos Econômicos 48, no. 4: 721-756, 2018.

Cariello, Rafael. À Procura de Leff. Piauí, no. 112, jan. 2016.

Delfim Netto, Antônio. Antônio Delfim Netto (1928). Em: Biderman, Ciro; Cozac, Luis Felipe; Rego, José Marcio, Conversas com Economistas Brasileiros. São Paulo: Editora 34, pp. 89-125, 1996.

Hespanhol, Gian Carlo M. G. "Um estudo sobre o pensamento econômico de Delfim Netto". Dissertação de mestrado. Departamento de História Econômica, FFLCH. Universidade de São Paulo. 2017.

Leff, Nathaniel; Delfim Netto, Antonio. "Import substitution. Foreign investment, and international disequilibrium in Brazil". Journal of Development Studies 2, no. 3: 218-233, 1966.

Macedo, Roberto. Antonio Delfim Netto. Estudos Avançados 15, no. 43: 375-388, 2001.

Pastore, Affonso Celso. Affonso Celso Pastore (1939). Em: Biderman, Ciro; Cozac, Luis Felipe; Rego, José Marcio, Conversas com Economistas Brasileiros. São Paulo: Editora 34, pp. 213-229, 1996.

Tavares, Maria da Conceição. Maria da Conceição Tavares (1930). Em: Biderman, Ciro; Cozac, Luis Felipe; Rego, José Marcio, Conversas com Economistas Brasileiros. São Paulo: Editora 34, pp. 127-151, 1996.

Seyler, William C. Doctoral Dissertations in Political Science in Universities of the United States and Canada. American Political Science Review, 60, no. 3: 778-803, 1966. 